\title{
Article
}

\section{Can taste be ergogenic?}

Best, Russ, McDonald, Kerin, Hurst, Philip and Pickering, Craig Available at http://clok.uclan.ac.uk/33393/

Best, Russ, McDonald, Kerin, Hurst, Philip and Pickering, Craig (2020) Can taste be ergogenic? European Journal of Nutrition . ISSN 1436-6207

It is advisable to refer to the publisher's version if you intend to cite from the work.

http://dx.doi.org/10.1007/s00394-020-02274-5

For more information about UCLan's research in this area go to

http://www.uclan.ac.uk/researchgroups/ and search for < name of research Group>.

For information about Research generally at UCLan please go to http://www.uclan.ac.uk/research/

All outputs in CLoK are protected by Intellectual Property Rights law, including Copyright law. Copyright, IPR and Moral Rights for the works on this site are retained by the individual authors and/or other copyright owners. Terms and conditions for use of this material are defined in the policies page.

\section{CLoK}

Central Lancashire online Knowledge www.clok.uclan.ac.uk

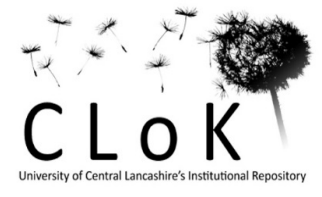




\section{Title: Can Taste be Ergogenic?}

2

\section{Authors}

$4 \quad$ Russ Best ${ }^{1,2}$

$5 \quad$ Kerin McDonald ${ }^{1}$

$6 \quad$ Philip Hurst ${ }^{3}$

$7 \quad$ Craig Pickering ${ }^{4}$

8

9 1. Centre for Sports Science and Human Performance, Wintec, Hamilton, 3288, New Zealand

10 2. School of Health and Social Care, Teesside University, Middlesbrough, TS1 3BX, UK

11 3. School of Human and Life Sciences, Canterbury Christ Church University, Canterbury, UK

12 4. Institute of Coaching and Performance, School of Sport and Wellbeing, University of Central 13 Lancashire, Preston PR1 2HE, UK 


\section{Abstract}

15 Taste is a homeostatic function that conveys valuable information such as energy density, readiness to 16 eat, or toxicity of foodstuffs. Taste is not limited to the oral cavity but affects multiple physiological 17 systems. In this review, we outline the ergogenic potential of substances that impart bitter, sweet, hot and cold tastes administered prior to and during exercise performance and whether the ergogenic benefits of taste are attributable to the placebo effect. Carbohydrate mouth rinsing seemingly improves endurance performance, along with a potentially ergogenic effect of oral exposure to both bitter tastants and caffeine - although subsequent ingestion of bitter mouth rinses is likely required to enhance performance. Hot and cold tastes may prove beneficial in circumstances where athletes' thermal state may be challenged. Efficacy is not limited to taste, but extends to the stimulation of targeted receptors in the oral cavity and throughout the digestive tract, relaying signals pertaining to energy availability and temperature to appropriate neural centres. Dose, frequency and timing of tastant application likely require personalisation to be most effective, and can be enhanced or confounded by factors that relate to the placebo effect, highlighting taste as a critical factor in designing and administering applied sports science interventions.

\section{Keywords}




\section{Introduction}

Taste is a homeostatic function that aids in deciding what to eat, and acts as a precursor for digestion [1]. Human taste and preferences are evolved due to nutrient availabilities within our ancestral environments [2], where they conveyed information such as energy density, readiness to eat, or toxicity $[1,3]$. Despite being the area most densely populated with taste receptors, taste is not strictly confined to the oral cavity, but frequently incorporates other sensory inputs from the upper digestive tract and auditory, olfactory and visual systems [1,4-9]. This is most evident in those who suffer with ageusia (loss of taste), or anosmia (loss of smell), and still respond physiologically to tastes $[3,10]$, demonstrating taste as a chemical interaction between a chemesthetic agent and receptors, which drives either ingestion or aversion and accompanying hedonic sensations.

Assessment of the physiological responses to taste has not escaped sports scientists, with many 'tastes' now investigated within the literature [11-15] with a view to attenuating fatigue or improving physical or cognitive performance. Depending upon the tastant investigated, impressions of energy availability $[16,17]$, thermal perceptions $[11,12,18]$ and central drive $[15,19]$ may be altered. Secondary outcomes may also include modifications in autonomic function [20-22], thirst [23,24] and ventilation [25-27], with further downstream effects depending upon whether tastants are ingested or simply rinsed around the oral cavity and expectorated.

These outcomes are likely useful to athletes, but depend heavily upon their exercise modality, prior exposure to and preference for specific tastants, as well as the availability of tastants during an exercise bout. Placebo effects associated with tastants cannot be excluded, and indeed may be maximised by including a carefully chosen taste component in personalised sports nutrition interventions, or matching tastes of interventions to other sensory expectations such as colour $[28,29]$. Previous work has asked whether "the [central] governor has a sweet tooth" [14]; in this review, we explore the ergogenic potential of different tastes administered prior to and during exercise performance. We also raise the question of whether the ergogenic benefits of taste are attributable to the placebo effect. Recommendations for athletes and practitioners, and future research directions are also provided throughout. 


\section{Sweet and Bitter Tastants and Athletic Performance}

62

\subsection{Carbohydrate}

The efficacy of carbohydrates as a means of supporting endurance performance is well established [30]. However, a clear, over-riding mechanism by which carbohydrate enhances performance is currently unknown; during exercise, only about a quarter of ingested carbohydrate enters peripheral circulation [31], with exogenous carbohydrate demonstrated to contribute only a small proportion of the carbohydrate oxidised during the late stages of prolonged exercise [32]. This lack of a clear metabolic mechanism lead to speculation that the consumption of carbohydrates during exercise may stimulate central pathways associated with sensations of reward or energy availability, which in turn has a performance-enhancing effect [33]. To test this hypothesis, researchers allowed subjects to rinse a carbohydrate solution around the mouth, but not ingest it, removing the metabolic effects of carbohydrate on performance. In the last decade, an exponential increase in research on this topic has been carried out, with a number of reviews [14,33-36] demonstrating a clear ergogenic effect of a carbohydrate mouth rinse on endurance performance, particularly in glycogen depleted participants.

Given that little carbohydrate is absorbed in the oral activity during mouth rinsing, the mechanism(s) by which carbohydrate mouth-rinses enhance performance are likely central in nature [14]. The tongue contains a number of taste receptors capable of detecting sweet stimuli [37] and these taste receptors when stimulated activate dopaminergic pathways and reward centres within the brain $[17,38]$. In turn, this increase in reward may enhance motivation to exercise, allowing the athlete to self-select higher exercise intensities, and reducing the impact of peripheral fatigue-associated signals under both the Central Governor [39] and psychobiological [40] models of fatigue. There may also be a feed-forward effect, whereby the activation of oral carbohydrate receptors suggests that energy is being consumed, allowing for an increase in exercise intensity, although this hypothesis has yet to be experimentally tested. 
At present, it appears that the ergogenic effects of a carbohydrate mouth-rinse are not taste related per se. This is demonstrated by the fact tasteless carbohydrates, such as maltodextrin, are ergogenic in a mouth-rinse solution [35], and also activate brain regions similarly to sweet tasting carbohydrates such as sucrose [17]. Similarly, artificial sweeteners provide a sweet taste, but a far smaller activation of key brain regions compared to sucrose [41]. Accordingly, it seems likely that it is the carbohydrate binding to as-of-yet unidentified oral carbohydrate receptors, as opposed to taste itself, that drives the ergogenic effects of a carbohydrate mouth rinse [14].

\subsection{Bitter tastants}

Building on the potential ergogenic effects of a sweet taste, as mediated by carbohydrate rinsing (detailed in section 2.1), Gam and colleagues explored the use of bitter tastants on exercise performance (reviewed in Gam et al., [19]). The potential relationship between bitter taste and enhanced exercise performance has a strong molecular underpinning, given that bitter tastants activate similar areas of the brain as sweet tastes [42], with these brain areas being implicated in aspects such as motor control and the processing of emotions [19].

In their first study exploring the ergogenic effects of a bitter tastant, Gam and colleagues [43] administered 14 competitive male cyclists with a bitter solution containing $2 \mathrm{mM}$ quinine, which was rinsed in the mouth for 10 seconds, and then ingested. The quinine solution enhanced mean power output in a 30 -second maximum cycle by $2.4 \%$ compared to an aspartame (sweet taste) mouth, and by $3.9 \%$ compared to water. In a subsequent study [44], a stronger concentration (10 $\mathrm{mM})$ of quinine was utilised, but the solution was only rinsed around the mouth, and not ingested. In this scenario, there was no ergogenic effect of the bitter solution on a 30-s cycle sprint, suggesting that the ingestion of the bitter solution is potentially important. The proposed mechanism underpinning the need for ingestion is that there are an increased number of bitter taste receptors beyond the oral cavity in the upper gastrointestinal tract [45] which are not activated following mouth rinse only. Outside the work of Gam and colleagues $[43,44,46]$, there is little additional research exploring the ergogenic effects of a bitter tastant, and so 
further research in this area is warranted. This would be particularly pertinent from a practical approach, with strong bitter tastants—-such as those used in the research by Gam and colleagues—able to induce nausea in some subjects upon ingestion [43]; given this information, further research exploring the optimal intensity of the bitter taste would likely be very useful.

\subsection{Caffeine}

Given the demonstrated ergogenic effects of an ingested bitter tastant [43,46], Pickering [15] recently reviewed whether caffeine-itself a bitter tastant [47] that has been shown to activate bitter taste receptors located in the oral cavity [48] — exerted some of it's well established ergogenic effects [49] via its bitter taste. A small number of studies [50-56] have utilised a caffeine mouth rinsing protocol as a method to enhance performance. Studies that demonstrated an ergogenic effect employed a repeated 6-s Wingate sprint protocol [50,53], or a self-paced endurance effort over 30-minutes [56]; whereas investigations that showed no effect employed either fixed work rate [51], progressive running [55] or repetitions to failure [52] models. Whilst the results are currently equivocal, there is a trend for no demonstrated performance enhancement when caffeine is rinsed around the mouth for both endurance and high-intensity exercise [15]. The reasons for this are currently unclear; it may be that caffeine's bitter taste is not ergogenic, that the caffeine solutions utilised were not sufficiently bitter to evoke an ergogenic effect, or that like quinine [44], ingestion of caffeine is required for its bitter taste to be ergogenic [54]. However, caffeine mouth rinses have been demonstrated to improve cognitive function during exercise [57] and limit mental fatigue [58] suggesting that there might be psychological ergogenic effect of caffeine mouth rinses — and therefore potentially caffeine's bitter taste—-for future research to uncover.

\subsection{Sweet and Bitter Tastes Section Summary}

Based on the research discussed here, there is a clear ergogenic effect of carbohydrate mouth rinsing on endurance performance [14], along with a potentially ergogenic effect of oral exposure to both bitter 
tastants [19] and caffeine [15] - although in the latter two cases, subsequent ingestion of the mouth

141 rinse is likely required to enhance performance. Regarding bitter tastants, it is believed that this 142 subsequent ingestion is required in order to further stimulate bitter taste receptors in the upper gastrointestinal tract [44]. These bitter taste receptors are not necessarily linked to gustatory neurons [59], meaning that this activation is not associated with "tasting" the bitterness. Additionally, tasteless carbohydrates evoke an identical ergogenic effect as sweet carbohydrates in a mouth rinse [35], whilst sweet tasting artificial sweeteners do not [33]. As such, it is important to note that the sensation of a particular taste may not be driving these ergogenic effects, but instead it is likely the stimulation of other receptors, which in turn act centrally to enhance performance [14].

\section{Thermal Tastants and athletic performance}

\subsection{Chilli and Capsaicin}

152 For millennia, humans have included spices such as chili peppers in their diets, experiencing and often enduring the associated pungent sensation of oral heat [60,61]. Mechanistically the sensation of increased temperature derives from the interaction between the compound capsaicin (8-methyl-Nvanillyl-6-nonenamide), and transient receptor potential vanilloid-1 proteins (TRPV1) [62]. TRPV1 is also stimulated when temperatures are elevated [63], hence foods containing capsaicin are perceived as being hot [62]. This perceptual heat is not limited to taste, with capsaicin also used in topical ointments, patches and sprays as a temporary but targeted analgesic [61]. The application of which is widely used by recreational and elite athletes to reduce joint and muscle pain, whereas the possible ergogenic properties of capsaicin taste and ingestion is an emerging field.

To date only four studies have investigated the ergogenic properties of capsaicin ingestion [64-66] or mouth swilling [12] in humans, and as such an array of protocols, dosages and performance measures have been assessed. Three studies have investigated the effect of acute supplementation of capsaicin (12mg), 45-minutes prior to athletic performance; 1500m running time trial [65], four sets of 70\% 1RM 
repeated squats to failure [13], and time to exhaustion during repeated 15 second treadmill running at $120 \% \mathrm{VO}_{2 \text { Peak }}$ with 15-second rest intervals [66]. Capsaicin supplementation improved 1500-m time trial performance (CAP $371.6 \pm 40.8$ seconds vs. Pla $376.7 \pm 39$ seconds), total mass lifted (CAP 3,919.4 $\pm 1,227.4 \mathrm{~kg}$ vs. Pla $3,179.6 \pm 942.4 \mathrm{~kg}$ ) and time to exhaustion (CAP $1530 \pm 515$ seconds vs. Pla 1342 \pm 446 seconds) compared to placebo. RPE was also significantly lower, although no differences in blood lactate were shown $[13,65]$. Researchers suggested that capsaicin supplementation may have stimulated activation of TRPV1 in skeletal muscle increasing calcium release at the sarcoplasmic reticulum; a phenomenon seen in rodent studies [67]. This increased influx of calcium may have resulted in greater actin and myosin interactions leading to improved performance. Alternatively, capsaicin has been shown to have an analgesic effect [61], which may have lowered RPE values and facilitated performance [13]. Increased endurance capabilities may also be facilitated by spared glycogen and concomitant increases in lipolysis through capsaicin ingestion [68-70].

The above literature suggests that ingesting capsaicin as a capsule is effective for improving sport performance. However, when capsaicin is ingested as food, the ergogenic effects are not consistent. A 7-day ingestion of cayenne herbal supplement totalling $25.8 \mathrm{mg}^{\text {. day }}{ }^{-1}$ of capsaicin, did not result in improved 30m sprint times, nor a reduction in RPE or muscle soreness scores [64]. Whereas, Lim et al., [71] showed the ingestion of $10 \mathrm{~g}$ of hot red peppers 2.5 hours prior to exercise (150w cycling for 60 minutes) significantly elevated both respiratory quotient and blood lactate levels at rest and during exercise, suggesting increased carbohydrate oxidation. The differences in supplementation type (cayenne vs. red peppers), dose amount (25.8 vs. $12 \mathrm{mg}$ ) and protocol (repeated vs. acute) likely contributed to the variation in efficacy; the higher dose in particular, may negatively influence GI motility[13]. This is supported by a rodent study that found swimming endurance was optimal when mice were supplemented with $10 \mathrm{mg} / \mathrm{kg}, 2$ hours prior to performance [72]. This dose and ingestion timing appear to be a 'sweet-spot', with doses or timings that fall below or exceed these values proving ineffective or deleterious to performance, respectively [73]. It should be noted that a similar dosage in 
a human diet would equate to $100 \mathrm{~g}$ of red chilli pepper consumption [74], which would be impractical and likely cause serious gastrointestinal (GI) discomfort [69].

As TRPV1 receptors are found in the oesophagus, stomach, intestine and colon [75], the possibility of GI discomfort is increased following capsaicin consumption. In a study where participants ingested capsaicin capsules, moderate visceral pain was reported following a median dose of $1 \mathrm{mg}$ [76]. Opheim \& Rankin's [64] repeated sprint study reported GI distress symptoms increased 6.3 times compared to placebo and resulted in 3 participants withdrawing from the study [64], thus capsaicin induced GI discomfort may deleteriously affect performance. A possible solution may be the use of a unique variety of chili pepper, $\mathrm{CH}-19$ Sweet, which contains capsiate, a non-pungent capsaicin analogue that has been shown to activate TRPV1 $[69,77]$ and return similar responses as capsaicin, including improving time to exhaustion in rodent studies [69,74]. Haramizu et al., [69] also observed no aversion to capsiate ingestion; like carbohydrate, efficacy of capsaicin supplementation may be less about the taste of the intervention, and more about the activation of desired receptors.

In each of the aforementioned human studies [64-66], capsaicin was delivered via a capsule. As a result, receptors in the oral cavity were by-passed, eliminating capsaicin's pungent oral sensation. Recently, Gibson et al., [12], employed a $0.2 \%$ capsaicin mouth swill every 10-minutes during repeated 6-second cycle ergometer sprints in the heat $\left(40^{\circ} \mathrm{C}, 40 \%\right.$ relative humidity). This delivery method (mouth swill) directly targets TRPV1 channels in the mouth and reduces possible GI discomfort; yet, results showed no difference in peak power, work performed or RPE across experimental groups (control, placebo, menthol and capsaicin mouth swills). Interestingly, thermal perception (comfort and sensation) was not altered after capsaicin mouth swill compared to control and placebo, but menthol trials reported significant improvements in thermal comfort [12].

Despite many reported health benefits from the regular consumption of capsaicin (e.g. improved cardiovascular function, diabetes control, etc. [61]), the effect of capsaicin on sports performance is 
limited. It would appear that acute supplementation (45-minutes prior to exercise) of low dose capsaicin $(12 \mathrm{mg})$ may induce an ergogenic response in near maximal exercise $[65,66]$. Further investigation on precise timing, dosage and delivery methods are required. Minimising GI discomfort should be a primary consideration for researchers while still effectively stimulating TRPV1 channels.

\subsection{Menthol}

Menthol imparts its familiar minty flavour via stimulation of transient receptor melastatin 8 (TRP-M8) receptors. These sodium voltage gated ion channels are especially concentrated in the trigeminal nerve , which innervates the oral cavity, and when stimulated mimic a 'cold' temperature range $\left(8-28^{\circ} \mathrm{C} ;[78]\right)$, feeling and tasting 'cool'. The effects of menthol are inversely proportional to the thickness of the stratum corneum $[11,79]$, hence application to the oral cavity often confers a greater stimulatory effect than topical menthol application $[11,80]$. Menthol can be experienced by anosmic individuals [81], emphasising its neurological mechanism $[82,83]$, but the ability to detect menthol has been shown to decline with age [84] suggesting higher menthol concentrations may be required to elicit ergogenic effects in masters athletes.

Menthol application to the oral cavity can be individualised by using a preferred menthol concentration and may be enhanced by using colour [29]. A relative dose is yet to be administered to athletes, but an experimental dose of $30 \mathrm{mg} / \mathrm{kg}$ was prescribed by food scientists investigating the effects of carbonation and menthol upon oral cooling [85]. Partnering menthol's chemosensory cooling effects with physiological coolants such as ice slurries may further enhance its efficacy [86-88], but there is an increased risk for overstimulation of the trigeminal system potentially resulting in "brain freeze" [8991].

Performance literature to date has assessed the effects of menthol mouth swilling upon cycling in intermittent [12] and time to exhaustion $[25,26,92]$ models, as well as running time trial performance [27,93]. Intermittent performance was not improved, however time to exhaustion and time trial performance demonstrate trivial-moderate improvements (Hedge's $g: 0.40 ; 0.04-0.76$ [18]). 
244 Concomitant improvements in thermal comfort and thermal sensation are noted following menthol 245 exposure [12,25,27,92,93], with an increase in ventilation also reported [25-27]. These effects are likely

246 mediated by TRP-M8 expression and stimulation of jugular and nodose neurons which provide 247 interoceptive feedback from the alimentary organs and the cardiorespiratory system $[94,95]$. This may 248 explain the increase in ventilation seen with menthol mouth swilling. The rate and volume of airflow 249 passing through the nasal canal also increase TRP-M8 activity and ventilation [96-98]. Whilst this can be contrived in the laboratory, it is likely that this effect is more apparent in ecologically valid settings with faster wind and performance velocities.

Despite participants reporting feeling cooler, no changes in body temperature have been reported to date following the oral application of menthol exclusively [12,25-27,92,93]. An emerging secondary effect of menthol use is an attenuation of thirst [23], however the potential ergogenic and contextual relevance of this is unknown as of yet, highlighting that menthol should be applied to sport cautiously. Thirst, more so than taste, conveys a homeostatic message regarding hydration status $[99,100]$; however, thirst can also be quenched by carbonated and cool/cold products [85,100-103] emphasising the role of TRP-M8 receptors in our somatosensory interpretation of cool and refreshing [104-107] and the potential for deception driven dehydration if water intake is attenuated in an event where hydration status is performance limiting e.g. ultramarathon $[108,109]$, or in athletes with abnormally high sweat rates [110].

\subsection{Thermal Tastants Section Summary}

Whilst the research pertaining to the TRP channel afferents capsaicin and menthol is in its infancy, in comparison to caffeine and carbohydrate, these thermal tastes may prove ergogenic under certain circumstances and likely serve to disrupt an athlete's perception of their thermal state, which may be ergogenic of itself. Individual sensory thresholds for effective doses likely exist, and timing of administration requires further elucidation, with the potential impact of these strategies on GI discomfort an important consideration. What is clear though, is that if capsaicin and menthol are to be 
supplemented, attaining meaningful doses via wholefoods would either be impractical or ineffective $[73,111]$

\section{The sweet taste of placebo}

273 The ergogenic effect of taste could be influenced by the placebo effect. The placebo effect is a desirable outcome resulting from a person's expected and/or learned response to a treatment or situation [28]. Placebo effects have shown to improve sport performance [112-114], with a systematic review reporting small to moderate effects for nutritional $(d=0.35)$ and mechanical $(d=0.47)$ ergogenic aids [115].

277 Placebo effects are often created within a psychosocial context that influences a person's response to a placebo. These include the interaction between the person receiving the placebo and the person administering it (e.g. participant and researcher), the environment in which it is delivered (e.g. laboratory) and sensory processes, such as colour, smell and taste [28]. The placebo effect is therefore a response to a signal, or set of signals, which convey information that trigger self-regulatory mechanisms.

While there are many theories to propose the underpinning mechanisms of the placebo effect (e.g. expectancy theory, classical conditioning), in this paper we adopt a broader and general conception that the placebo effect of taste could be explained through an anticipation on resource allocation. Beedie et al., [116] recently argued that the brain modulates and anticipates the relationship between a signal (e.g. taste) and the body, which regulates subsequent resource allocation. Based on this understanding, the taste of glucose, for example, signals to the brain that resources will soon be available, which in turn, regulates the resources allocated. Theoretically, if a placebo tastes like glucose, the brain would anticipate that glucose has been received and subsequently offloads more resources. In short, the placebo effect may impact the ergogenic effect of taste through its application of signalling to the brain 
that more resources are available, which sets in motion a chain of self-regulatory responses that produce an improvement in performance ${ }^{1}$.

Research into taste and the placebo effect on sport performance is limited. However, early research into the placebo effect provides compelling evidence of the significant role taste can have for inducing placebo effects and influencing physiological responses. Ader and Cohen [119] administered a distinctly flavoured drink followed by a toxic agent capable of suppressing the immune system. After repeat administrations of the drink and toxic agent, the taste of the drink alone resulted in an immunosuppression response. Similarly, Olness and Ader [120] reported a clinical case study of a child with lupus erythematosus (an autoimmune disease) after administering cyclophosphamide paired with taste and smell stimuli similar to Ader and Cohen [119]. After initial pairings of the drug with the sensory stimuli, the taste alone was administered and the patient's symptoms improved after 12 months. The publication of these studies resulted in a proliferation of similar taste aversion research [121], which has demonstrated the influence of taste and anticipatory responses in inducing placebo effects.

It is likely that placebo effects of taste are mediated by neurobiological pathways. While there are many neurobiological pathways associated with the placebo effect, a large amount of research has investigated the role of the endogenous opioid system [122]. This is not surprising given that $\mu$-opioid receptors are located throughout the brain are critical for the reduction of pain [123]. Amanzio and Benedetti [124] exposed participants to a conditioning procedure of the opioid drug buprenorphine and measured pain tolerance and endogenous opioid release in the brain. After repeat trials of the opioid drug, when replaced with saline, pain tolerance significantly increased compared to baseline, which was mediated by increases in activation of the endogenous opioid system. Similar results have been reported

\footnotetext{
${ }^{1}$ Providing an explanation for why this occurs is outside the scope of the paper, but we refer the reader to the work of Humphrey [117] and Miller, Colloca and Kaptchuk [118], who offer a more thorough explanation.
} 
elsewhere [125,126], and highlight the significant mediating role the endogenous opioid system has for inducing placebo effects.

315 Like placebo effects, taste receptors can also mediate the release of endogenous opioids $[127,128]$.

316 Although the magnitude of the effect can depend on age and gender[129], the sweet taste of glucose and sucrose can modulate the production of endogenous opioid release [130], whereas administration of sucrose directly to the stomach has no effect [131]. This suggests that sweet taste can have analgesic effects. However, where the ergogenic effects of taste tend to report pain relieving effects, placebo effects are often the result of similar mechanisms e.g. pain, fatigue and perception of effort $[113,114,132]$. While taste could have direct neurobiological mechanisms, there is evidence that placebo effects can mimic the neurobiological pathways of a treatment [133]. It could be suggested that the same pathways activated by taste are also activated by the administration of a placebo. We are by no means implying that the ergogenic effects of taste are the result of a placebo effect, but we, like others $[28,134,135]$, are suggesting that the mechanisms in which a nutritional ergogenic aid exerts it effect is likely to be a combination of both. As with most treatments and interventions on sport performance, the ergogenic effect of taste will be influenced via the placebo effect (see Beedie, Foad \& Hurst [134]). It is likely that they are both components of a self-regulatory system that act as signals to the brain for resource allocation, which are likely mediated by neurobiological pathways, such as the endogenous opioid system. However, there is a lack of research in sport explicitly examining whether the ergogenic effect of taste and the placebo effect activate shared or distinct mechanisms. To help develop knowledge and understanding in this area beyond speculation, empirical research is needed that examines whether the placebo effect of taste is partially or fully responsible for its ergogenic effect.

\section{Practical Recommendations}

Tastants have the potential to be employed as ergogenic strategies during sport and exercise performance, with tentative evidence supporting the efficacy of sweet [14], bitter [19], spicy [65], and cooling [11] tastants. However, consideration of event demands, nutritional state of the athlete and athletes' performance environment are strongly recommended to successfully employ taste related strategies in athletic settings. Developing taste related strategies with regular input from athletes also 
allows for maximisation of other sensory factors such as colour and odour, which may confer further psychological and performance benefits through placebo effects. At present, given the evidence discussed, we can tentatively suggest that athletes undertaking aerobic endurance and/or repeated high intensity efforts may benefit from the use of sweet-tasting carbohydrate or bitter-tasting beverages, with the addition of caffeine. Similar to carbohydrate and bitter tastants, athletes may benefit from menthol supplementation during endurance exercise, whereas capsaicin ingestion may be of use during activities that are near maximal in nature. Menthol may be administered as a mouth rinse, at concentrations between $0.01 \%$ and $0.1 \%$ [29] and can be employed throughout the exercise bout. Capsaicin may be ingested as a capsule containing a $12 \mathrm{mg}$ dose, 45 minutes prior to maximal effort exercise. All strategies should be trialled prior to use in competition, and the potential for GI disturbance using a validated tool [136]. In using these beverages, there may be additional advantages - and no obvious negativesgained by the athlete from rinsing the liquid around the oral cavity prior to ingestion. Furthermore, augmented ergogenic effects may occur if the athlete recognises a taste as performance-enhancing via expectancy and placebo effects [15].

\section{Future Research Directions}

Future research in taste and athletic performance should consider investigating differences between tasting, swilling and ingesting, and their subsequent effects upon performance; this is especially important given the emerging research that ingestion of bitter tastants such as quinine and caffeine is required to maximise their ergogenic effects above those demonstrated through mouth-rinse only [15] Each strategy exposes tastants to different densities and volumes of taste receptors, and may be accompanied by other sports nutrition strategies, so the inclusion of tastants need to be weighed against established ergogenic strategies such as maintaining carbohydrate availability during an event. The optimal dose of each tastant, including their physiological tolerance and associated side-effects, also represent an important practical avenue for future research. Similarly, habituation to tastants is also worthy of investigation, as we must understand the time course of these strategies to maximise their efficacy. It is acknowledged that there is likely a strong genetic underpinning to preference and responses to tastes $[137,138]$. Some work has already begun in caffeine $[139,140]$, carbohydrate 
367 [141,142] and TRP-M8 [143], but understanding the genetic contributions to liking, or tolerance for,

368 thermal tastes and bitterness may confer further benefits beyond athletic populations.

\section{7. Conclusion}

370 This review synthesises the evidence from a variety of tastes that have shown ergogenic promise with

371 respect to athletic performance. This efficacy is not limited to taste per se, but extends to the stimulation

372 of targeted receptors in the oral cavity and throughout the digestive tract, which relay signals pertaining

373 to energy availability and temperature to appropriate neural centres. Timing of tastant application, dose

374 and frequency of application likely require personalisation to be most effective, and can be enhanced

375 or confounded by factors that relate to the placebo effect. 
378 1. Breslin PAS. An Evolutionary Perspective on Food Review and Human Taste. Current Biology. 379 2013;23:R409-18.

380 2. Bachmanov AA, Bosak NP, Lin C, Matsumoto I, Ohmoto M, Reed DR, et al. Genetics of taste receptors. Curr. Pharm. Des. 2014;20:2669-83.

4. Devillier P, Naline E, Grassin-Delyle S. The pharmacology of bitter taste receptors and their role in human airways. Pharmacology and Therapeutics. 2015;155:11-21.

5. Freund JR, Lee RJ. Taste receptors in the upper airway. World Journal of OtorhinolaryngologyHead and Neck Surgery. 2018;4:67-76.

6. Spence C. On the psychological impact of food colour. Flavour. 2015;4:21.

7. Skinner M, Eldeghaidy S, Ford R, Giesbrecht T, Thomas A, Francis S, et al. Variation in thermally induced taste response across thermal tasters. Physiology \& Behavior. 2018;188:67-78.

8. Spence C. Just how much of what we taste derives from the sense of smell? Flavour. 2015;:1-10.

9. Small DM. Flavor is in the brain. Physiology \& Behavior. 2012;107:540-52.

10. Frasnelli J, Albrecht J, Bryant B, Lundström JN. Perception of specific trigeminal chemosensory agonists. Neuroscience. 2011;189:377-83.

11. Stevens CJ, Best R. Menthol: A Fresh Ergogenic Aid for Athletic Performance. Sports Med. 2017;47:1035-42.

12. Gibson OR, Wrightson JG, Hayes M. Intermittent sprint performance in the heat is not altered by augmenting thermal perception via L-menthol or capsaicin mouth rinses. European Journal of Applied Physiology. 2018;46:936-12.

13. de Freitas MC, Cholewa JM, Freire RV, Carmo BA, Bottan J, Bratfich M, et al. Acute capsaicin supplementation improves resistance training performance in trained men. The Journal of Strength \& 401 Conditioning Research. 2017;:1-21.

14. Burke LM, Maughan RJ. The Governor has a sweet tooth - Mouth sensing of nutrients to enhance sports performance. European Journal of Sport Science. 2014;15:29-40.

15. Pickering C. Are caffeine's performance-enhancing effects partially driven by its bitter taste? Medical Hypotheses. 2019;131:109301.

16. Fares E-JM, Kayser B. Carbohydrate Mouth Rinse Effects on Exercise Capacity in Pre- and 407 Postprandial States. Journal of Nutrition and Metabolism. 2011;2011:1-6.

17. Chambers ES, Bridge MW, Jones DA. Carbohydrate sensing in the human mouth: effects on exercise performance and brain activity. The Journal of Physiology. 2009;587:1779-94. meta-analysis. Journal of Science and Medicine in Sport. 2019;22:707-15. 
20. Rousmans S, Robin O, Dittmar A, Vernet-Maury E. Autonomic nervous system responses associated with primary tastes. Chemical Senses. 2000;25:709-18.

21. Leterme A, Brun L, Dittmar A, Robin O. Autonomic nervous system responses to sweet taste: Evidence for habituation rather than pleasure. Physiology \& Behavior. 2008;93:994-9.

22. Michlig S, Merlini JM, Beaumont M, Ledda M, Tavenard A, Mukherjee R, et al. Effects of TRP channel agonist ingestion on metabolism and autonomic nervous system in a randomized clinical trial of healthy subjects. Nature. $2016 ;: 1-12$.

23. Eccles R. Role of cold receptors and menthol in thirst, the drive to breathe and arousal. Appetite. 2000;34:29-35.

24. Eccles R, Du-Plessis L, Dommels Y, Wilkinson JE. Cold pleasure. Why we like ice drinks, icelollies and ice cream. Appetite. 2013;71:357-60.

25. Flood TR, Waldron M, Jeffries O. Oral L-menthol reduces thermal sensation, increases work-rate and extends time to exhaustion, in the heat at a fixed rating of perceived exertion. European Journal of Applied Physiology. 2017;117:1501-12.

26. Mündel T, Jones DA. The effects of swilling an 1(-)-menthol solution during exercise in the heat. European Journal of Applied Physiology. 2009;109:59-65.

27. Stevens CJ, Thoseby B, Sculley DV, Callister R, Taylor L, Dascombe BJ. Running performance and thermal sensation in the heat are improved with menthol mouth rinse but not ice slurry ingestion. J Appl Physiolo. 2016;26:1209-16.

28. Beedie C, Benedetti F, Barbiani D, Camerone E, Cohen E, Coleman D, et al. Consensus statement on placebo effects in sports and exercise: The need for conceptual clarity, methodological rigour, and the elucidation of neurobiological mechanisms. European Journal of Sport Science. 2018;18:1383-9.

29. Best R, Spears I, Hurst P, Berger N. The Development of a Menthol Solution for Use during Sport and Exercise. Beverages. 2018;4:44-10.

30. Stellingwerff T, Cox GR. Systematic review: Carbohydrate supplementation on exercise performance or capacity of varying durations 1. Appl. Physiol. Nutr. Metab. 2014;39:998-1011.

31. McConell GK, Canny BJ, Daddo MC, Nance MJ, Snow RJ. Effect of carbohydrate ingestion on glucose kinetics and muscle metabolism during intense endurance exercise. Journal of Applied Physiology. 2000;89:1690-8.

32. Carter JM, Jeukendrup AE, Mann CH, Jones DA. The effect of glucose infusion on glucose kinetics during a 1-h time trial. Medicine \& Science in Sports \& Exercise. 2004;36:1543-50.

33. Rollo DI, Williams C. Effect of Mouth-Rinsing Carbohydrate Solutions on Endurance Performance. Sports Med. 2011;41:449-61.

34. Jeukendrup AE, Chambers ES. Oral carbohydrate sensing and exercise performance. Current Opinion in Clinical Nutrition \& Metabolic Care. 2010;13:447-51.

35. de Ataide e Silva T, Di Cavalcanti Alves de Souza ME, de Amorim JF, Stathis CG, Leandro CG, Lima-Silva AE. Can carbohydrate mouth rinse improve performance during exercise? A systematic review. Nutrients. 2013;6:1-10. 
Carbohydrate Mouth Rinse on Cycling Time Trial Performance: A Systematic Review and MetaAnalysis. Sports Med. 2019;49:57-66.

37. Berthoud H-R. Neural systems controlling food intake and energy balance in the modern world. Current Opinion in Clinical Nutrition \& Metabolic Care. 2003;6:615-20.

38. de Araujo IE, Ren X, Ferreira JG. Metabolic Sensing in Brain Dopamine Systems. In: Meyerhof W, Beisiegel U, Joost H-G, editors. Sensory and Metabolic Control of Energy Balance. Berlin, Heidelberg: Springer Berlin Heidelberg; 2010. pp. 69-86.

39. Noakes TD. The central governor model of exercise regulation applied to the marathon. Sports Med. 2007;37:374-7.

40. Marcora S. Perception of effort during exercise is independent of afferent feedback from skeletal muscles, heart, and lungs. Journal of Applied Physiology. 2009;106:2060-2.

41. Frank GKW, Oberndorfer TA, Simmons AN, Paulus MP, Fudge JL, Yang TT, et al. Sucrose activates human taste pathways differently from artificial sweetener. NeuroImage. 2008;39:1559-69.

42. Zald DH, Hagen MC, Pardo JV. Neural correlates of tasting concentrated quinine and sugar solutions. J. Neurophysiol. 2002;87:1068-75.

43. Gam S, Guelfi KJ, Fournier PA. Mouth rinsing and ingesting a bitter solution improves sprint cycling performance. Medicine \& Science in Sports \& Exercise. 2014;46:1648-57.

44. Gam S, Tan M, Guelfi KJ, Fournier PA. Mouth rinsing with a bitter solution without ingestion does not improve sprint cycling performance. European Journal of Applied Physiology. 2015;115:129-38.

45. Behrens M, Foerster S, Staehler F, Raguse J-D, Meyerhof W. Gustatory expression pattern of the human TAS2R bitter receptor gene family reveals a heterogenous population of bitter responsive taste receptor cells. J. Neurosci. Society for Neuroscience; 2007;27:12630-40.

46. Gam S, Guelfi KJ, Hammond G, Fournier PA. Mouth rinsing and ingestion of a bitter-tasting solution increases corticomotor excitability in male competitive cyclists. European Journal of Applied Physiology. 2015;115:2199-204.

47. Poole RL, Tordoff MG. The Taste of Caffeine. Journal of Caffeine Research. 2017;7:39-52.

48. Meyerhof W, Batram C, Kuhn C, Brockhoff A, Chudoba E, Bufe B, et al. The molecular receptive ranges of human TAS2R bitter taste receptors. Chemical Senses. 2010;35:157-70.

49. Grgic J, Grgic I, Pickering C, Schoenfeld BJ, Bishop DJ, Pedisic Z. Wake up and smell the coffee: caffeine supplementation and exercise performance-an umbrella review of 21 published metaanalyses. British Journal of Sports Medicine. 2019;:bjsports-2018-100278.

50. Beaven CM, Maulder P, Pooley A, Kilduff L, Cook C. Effects of caffeine and carbohydrate mouth rinses on repeated sprint performance. Appl. Physiol. Nutr. Metab. 2013;38:633-7.

51. Doering TM, Fell JW, Leveritt MD, Desbrow B, Shing CM. The effect of a caffeinated mouthrinse on endurance cycling time-trial performance. Int J Sport Nutr Exerc Metab. 2014;24:90-7.

52. Clarke ND, Kornilios E, Richardson DL. Carbohydrate and Caffeine Mouth Rinses Do Not Affect Maximum Strength and Muscular Endurance Performance. J Strength Cond Res. 2015;29:2926-31.

53. Kizzi J, Sum A, Houston FE, Hayes LD. Influence of a caffeine mouth rinse on sprint cycling 
following glycogen depletion. European Journal of Sport Science. 2016;:1-8.

54. Pataky MW, Womack CJ, Saunders MJ, Goffe JL, D'Lugos AC, El-Sohemy A, et al. Caffeine and 3-km cycling performance: Effects of mouth rinsing, genotype, and time of day. J Appl Physiolo. John Wiley \& Sons, Ltd (10.1111); 2016;26:613-9.

55. Dolan P, Witherbee KE, Peterson KM, Kerksick CM. Effect of Carbohydrate, Caffeine, and Carbohydrate + Caffeine Mouth Rinsing on Intermittent Running Performance in Collegiate Male Lacrosse Athletes. J Strength Cond Res. 2017;31:2473-9.

56. Bottoms L, Hurst H, Scriven A, Lynch F, Bolton J, Vercoe L, et al. The effect of caffeine mouth rinse on self-paced cycling performance. Comparative Exercise Physiology. 2014;10:239-45.

57. Pomportes L, Brisswalter J, Casini L, Hays A, Davranche K. Cognitive Performance Enhancement Induced by Caffeine, Carbohydrate and Guarana Mouth Rinsing during Submaximal Exercise. Nutrients. 2017;9:589.

58. Van Cutsem J, De Pauw K, Marcora S, Meeusen R, Roelands B. A caffeine-maltodextrin mouth rinse counters mental fatigue. Psychopharmacology. 2018;235:947-58.

59. Rozengurt E. Taste receptors in the gastrointestinal tract. I. Bitter taste receptors and alphagustducin in the mammalian gut. Am. J. Physiol. Gastrointest. Liver Physiol. 2006;291:G171-7.

60. Macneish RS. Ancient Mesoamerican Civilization. Science. 1964;143:531-7.

61. Fattori V, Hohmann MSN, Rossaneis AC, Pinho-Ribeiro FA, Verri WA. Capsaicin: Current Understanding of Its Mechanisms and Therapy of Pain and Other Pre-Clinical and Clinical Uses. Molecules. 2016;21:844.

62. Simon SA, de Araujo IE. The salty and burning taste of capsaicin. J. Gen. Physiol. 2005;125:5314.

63. Caterina MJ, Schumacher MA, Tominaga M, Rosen TA, Levine JD, Julius D. The capsaicin receptor: a heat-activated ion channel in the pain pathway. Nature. 1997;389:816-24.

64. Opheim MN, Rankin JW. Effect of capsaicin supplementation on repeated sprinting performance. J Strength Cond Res. 2012;26:319-26.

65. de Freitas MC, Cholewa JM, Gobbo LA, de Oliveira JVNS, Lira FS, Rossi FE. Acute Capsaicin Supplementation Improves 1,500-m Running Time-Trial Performance and Rate of Perceived Exertion in Physically Active Adults. J Strength Cond Res. 2018;32:572-7.

66. de Freitas MC, Billaut F, Panissa VLG, Rossi FE, Figueiredo C, Caperuto EC, et al. Capsaicin supplementation increases time to exhaustion in high-intensity intermittent exercise without modifying metabolic responses in physically active men. European Journal of Applied Physiology. 2019;119:971-9.

67. Lotteau S, Ducreux S, Romestaing C, Legrand C, Van Coppenolle F. Characterization of functional TRPV1 channels in the sarcoplasmic reticulum of mouse skeletal muscle. Kanzaki M, editor. PLoS ONE. 2013;8:e58673.

68. Glickman-Weiss EL, Hearon CM, Nelson AG, Day R. Does capsaicin affect physiologic and thermal responses of males during immersion in 22 degrees C? Aviat Space Environ Med. 1998;69:1095-9. 
69. Haramizu S, Mizunoya W, Masuda Y, Ohnuki K, Watanabe T, Yazawa S, et al. Capsiate, a nonpungent capsaicin analog, increases endurance swimming capacity of mice by stimulation of vanilloid receptors. Bioscience, Biotechnology, and Biochemistry. 2006;70:774-81.

70. Shin KO, Yeo NH, Kang S. Autonomic nervous activity and lipid oxidation postexercise with capsaicin in the humans. J Sports Sci Med. 2010;9:253-61.

71. Lim K, Yoshioka M, Kikuzato S, Kiyonaga A, Tanaka H, Shindo M, et al. Dietary red pepper ingestion increases carbohydrate oxidation at rest and during exercise in runners. Medicine \& Science in Sports \& Exercise. 1997;29:355-61.

72. Oh T-W, Ohta F. Dose-dependent effect of capsaicin on endurance capacity in rats. British Journal of Nutrition. 2003;90:515-20.

73. Kim KM, Kawada T, Ishihara K, Inoue K, Fushiki T. Increase in swimming endurance capacity of mice by capsaicin-induced adrenal catecholamine secretion. Bioscience, Biotechnology, and Biochemistry. 1997;61:1718-23.

74. Kim KM, Kawada T, Ishihara K, Inoue K, Fushiki T. Swimming capacity of mice is increased by oral administration of a nonpungent capsaicin analog, stearoyl vanillylamide. J. Nutr. 1998;128:197883.

75. Yu X, Yu M, Liu Y, Yu S. TRP channel functions in the gastrointestinal tract. Semin Immunopathol. 2015;38:385-96.

76. Li X, Cao Y, Wong RKM, Ho KY, Wilder-Smith CH. Visceral and somatic sensory function in functional dyspepsia. Neurogastroenterol. Motil. 2013;25:246-53-e165.

77. Iida T, Moriyama T, Kobata K, Morita A, Murayama N, Hashizume S, et al. TRPV1 activation and induction of nociceptive response by a non-pungent capsaicin-like compound, capsiate. Neuropharmacology. 2003;44:958-67.

78. Patel T, Ishiuji Y, Yosipovitch G. Menthol: A refreshing look at this ancient compound. Journal of the American Academy of Dermatology. 2007;57:873-8.

79. Watson HR, Hems R, Rowsell DG, Spring DJ. New compounds with the menthol cooling effect. J Soc Cosmet Chem. 1978;29:185-200.

80. Best R, Payton S, Spears I, Riera F, Berger N. Topical and Ingested Cooling Methodologies for Endurance Exercise Performance in the Heat. Sports. 2018;6:11-1.

81. Cometto-Muñiz JE, Cain WS. Thresholds for odor and nasal pungency. Physiology \& Behavior. 1990;48:719-25.

82. Viana F. Chemosensory Properties of the Trigeminal System. ACS Chem. Neurosci. 2011;2:3850 .

83. Kollndorfer K, Kowalczyk K, Frasnelli J, Hoche E, Unger E, Mueller CA, et al. Same Same but Different. Different Trigeminal Chemoreceptors Share the Same Central Pathway. McKemy DD, editor. PLoS ONE. 2015;10:e0121091-12.

84. Murphy C. Age-related effects on the threshold, psychophysical function, and pleasantness of menthol. J Gerontol. 1983;38:217-22.

85. Saint-Eve A, Déléris I, Feron G, Ibarra D, Guichard E, Souchon I. How trigeminal, taste and 
aroma perceptions are affected in mint-flavored carbonated beverages. Food Quality and Preference. 2010;21:1026-33.

86. Riera F, Trong TT, Sinnapah S, Hue O. Physical and Perceptual Cooling with Beverages to Increase Cycle Performance in a Tropical Climate. Hayashi N, editor. PLoS ONE. 2014;9:e103718-7.

87. Riera F, Trong T, Rinaldi K, Hue O. Precooling does not Enhance the Effect on Performance of Midcooling with Ice-Slush/Menthol. Int J Sports Med. 2016;37:1025-31.

88. Tran Trong T, Riera F, Rinaldi K, Briki W, Hue O. Ingestion of a cold temperature/menthol beverage increases outdoor exercise performance in a hot, humid environment. Romanovsky AA, editor. PLoS ONE. 2015;10:e0123815.

89. Siegel R, Laursen PB. Keeping Your Cool. Sports Med. 2012;42:89-98.

90. Mages S, Hensel O, Zierz AM, Kraya T, Zierz S. Experimental provocation of "ice-cream headache" by ice cubes and ice water. Cephalalgia. 2017;37:464-9.

91. Hulihan J. Ice cream headache. BMJ. 1997;314:1364.

92. Jeffries $\mathrm{O}$, Goldsmith M, Waldron M. L-Menthol mouth rinse or ice slurry ingestion during the latter stages of exercise in the heat provide a novel stimulus to enhance performance despite elevation in mean body temperature. European Journal of Applied Physiology. 2018;118:2435-42.

93. Stevens CJ, Bennett KJM, Sculley DV, Callister R, Taylor L, Dascombe BJ. A comparison of mixed-method cooling interventions on pre-loaded running performance in the heat. The Journal of Strength \& Conditioning Research. 2016:1-28.

94. Kupari J, Häring M, Agirre E, Castelo-Branco G, Ernfors P. An Atlas of Vagal Sensory Neurons and Their Molecular Specialization. CellReports. 2019;27:2508-2523.e4.

95. Kaczyńska K, Szereda-Przestaszewska M. Nodose ganglia-modulatory effects on respiration. Physiol Res. 2013;62:227-35.

96. Baraniuk JN, Merck SJ. Nasal reflexes: implications for exercise, breathing, and sex. Curr Allergy Asthma Rep. 2008;8:147-53.

97. Naito K, Komori M, Kondo Y, Takeuchi M, Iwata S. The effect of 1-menthol stimulation of the major palatine nerve on subjective and objective nasal patency. Auris Nasus Larynx. 1997;24:159-62.

98. Eccles R. Menthol: Effects on nasal sensation of airflow and the drive to breathe. Curr Allergy Asthma Rep. 2003;3:210-4.

99. Thornton SN. Thirst and hydration: Physiology and consequences of dysfunction. Physiology \& Behavior. 2010;100:15-21.

100. van Belzen L, Postma EM, Boesveldt S. How to quench your thirst. The effect of water-based products varying in temperature and texture, flavour, and sugar content on thirst. Physiology \& Behavior. 2017;180:45-52.

101. Peyrot des Gachons C, Avrillier J, Gleason M, Algarra L, Zhang S, Mura E, et al. Oral Cooling and Carbonation Increase the Perception of Drinking and Thirst Quenching in Thirsty Adults. Glendinning JI, editor. PLoS ONE. 2016;11:e0162261-12. 
610 103. Lee JKW, Shirreffs SM. The influence of drink temperature on thermoregulatory responses 611 during prolonged exercise in a moderate environment. Journal of Sports Sciences. 2007;25:975-85.

612 104. Labbe D, Almiron-Roig E, Hudry J, Leathwood P, Schifferstein HNJ, Martin N. Sensory basis of 613 refreshing perception: Role of psychophysiological factors and food experience. Physiology \& 614 Behavior. 2009;98:1-9.

615 105. Labbe D, Gilbert F, Antille N, Martin N. Sensory determinants of refreshing. Food Quality and 616 Preference. 2009;20:100-9.

617 106. Fenko A, Schifferstein HNJ, Huang T-C, Hekkert P. What makes products fresh: The smell or 618 the colour? Food Quality and Preference. 2009;20:372-9.

619 107. Eccles R, Du-Plessis L, Dommels Y, Wilkinson JE. Cold pleasure. Why we like ice drinks, ice620 lollies and ice cream. Appetite. 2013;71:357-60.

621 108. Best R, Barwick B, Best A, Berger N, Harrison C, Wright M, et al. Changes in Pain and 622 Nutritional Intake Modulate Ultra-Running Performance: A Case Report. Sports. 2018;6:111-3.

623 109. Hoffman MD, Stellingwerff T, Costa RJS. Considerations for ultra-endurance activities: part 2 hydration. Research in Sports Medicine. 2018;00:1-13.

110. Armstrong LE, Hubbard RW, Jones BH, Daniels JT. Preparing Alberto Salazar for the Heat of the 1984 Olympic Marathon. The Physician and Sportsmedicine. 2016;14:73-81.

111. Shepherd K, Peart DJ. Aerobic capacity is not improved following 10-day supplementation with peppermint essential oil. Appl. Physiol. Nutr. Metab. 2017;42:558-61.

112. Hurst P, Foad A, Coleman D, Beedie C. Athletes Intending to Use Sports Supplements Are More

Likely to Respond to a Placebo. Medicine \& Science in Sports \& Exercise. 2017;49:1877-83.

113. Hurst P, Schiphof-Godart L, Hettinga F, Roelands B, Beedie C. Improved 1000-m running performance and pacing strategy with caffeine and placebo effect: a balanced placebo design study. Int J Physiol Perf. 2019, 9 (1): 1-6

114. Ross R, Gray CM, Gill JMR. Effects of an Injected Placebo on Endurance Running Performance. Medicine \& Science in Sports \& Exercise. 2015;47:1672-81.

115. Hurst P, Schipof-Godart L, Szabo A, Raglin J, Hettinga F, Roelands B, et al. The Placebo and Nocebo effect on sports performance: A systematic review. European Journal of Sport Science. 2019;46:1-14. methods and findings from neuroscience to better understand placebo and nocebo effects in sport. European Journal of Sport Science. 2019;7:1-13. 2002. p. 225.246. 
120. Olness K, Ader R. Conditioning as an adjunct in the pharmacotherapy of lupus erythematosus. $\mathbf{J}$

Dev Behav Pediatr. 1992;13:124-5.

651

652

653

654

655

656

657

658

659

660

661

662

663

664

665

666

667

668

669

670

671

672

673

674

121. Smits RM, Veldhuijzen DS, Wulffraat NM, Evers AWM. The role of placebo effects in immunerelated conditions: mechanisms and clinical considerations. Expert Rev Clin Immunol. 2018;14:76170.

122. Benedetti F. Placebo and the new physiology of the doctor-patient relationship. Physiological Reviews. 2013;93:1207-46.

123. Colloca L. The Placebo Effect in Pain Therapies. Annu. Rev. Pharmacol. Toxicol. 2019;59:191211.

124. Amanzio M, Benedetti F. Neuropharmacological dissection of placebo analgesia: expectationactivated opioid systems versus conditioning-activated specific subsystems. J. Neurosci. 1999;19:484-94.

125. Wager TD, Scott DJ, Zubieta J-K. Placebo effects on human $\mu$-opioid activity during pain. Proc Natl Acad Sci USA. 2007;104:11056-61.

126. Zubieta J-K, Bueller JA, Jackson LR, Scott DJ, Xu Y, Koeppe RA, et al. Placebo Effects Mediated by Endogenous Opioid Activity on $\mu$-Opioid Receptors. J. Neurosci. Society for Neuroscience; 2005;25:7754-62.

127. Jain R, Mukherjee K, Singh R. Influence of sweet tasting solutions on opioid withdrawal. Brain Res. Bull. 2004;64:319-22.

128. Lewkowski MD, Young SN, Ghosh S, Ditto B. Effects of opioid blockade on the modulation of pain and mood by sweet taste and blood pressure in young adults. Pain. 2008;135:75-81.

129. Wise PM, Breslin PAS, Dalton P. Effect of taste sensation on cough reflex sensitivity. Lung. 2014;192:9-13.

130. Pelchat ML. Of human bondage: food craving, obsession, compulsion, and addiction. Physiology \& Behavior. 2002;76:347-52.

131. Ramenghi LA, Evans DJ, Levene MI. "Sucrose analgesia": absorptive mechanism or taste perception? Arch. Dis. Child. Fetal Neonatal Ed. 1999;80:F146-7.

132. Beedie CJ, Stuart EM, Coleman DA, Foad AJ. Placebo effects of caffeine on cycling performance. Medicine \& Science in Sports \& Exercise. 2006;38:2159-64.

133. Benedetti F, Dogue S. Different Placebos, Different Mechanisms, Different Outcomes: Lessons for Clinical Trials. Eldabe S, editor. PLoS ONE. 2015;10:e0140967.

134. Beedie C, Foad A, Hurst P. Capitalizing on the Placebo Component of Treatments. Current Sports Medicine Reports. 2015. pp. 284-7.

135. Halson SL, Martin DT. Lying to win-placebos and sport science. Int J Sports Physiol Perform. 2013;8:597-9.

136. Gaskell SK, Snipe RMJ, Costa RJS. Test Re-Test Reliability of a Modified Visual Analogue Scale Assessment Tool for Determining Incidence and Severity of Gastrointestinal Symptoms in Response to Exercise Stress. Int J Sports Nutr Exerc Metab. 2019;:1-26. 
137. Newcomb RD, Xia MB, Reed DR. Heritable differences in chemosensory ability among humans.

688 Flavour. 2012.

689 138. Pickering C, Kiely J. What Should We Do About Habitual Caffeine Use in Athletes? Sports 690 Med. 2018;:1-10.

691 139. Guest N, Corey P, Vescovi J, El-Sohemy A. Caffeine, CYP1A2 Genotype, and Endurance

692 Performance in Athletes. Medicine \& Science in Sports \& Exercise. 2018;50:1570-8.

693 140. Loy BD, O'Connor PJ, Lindheimer JB, Covert SF. Caffeine Is Ergogenic for Adenosine A 694 2AReceptor Gene ( ADORA2A) T Allele Homozygotes: A Pilot Study. Journal of Caffeine Research. 695 2015;5:73-81.

696 141. Søberg S, Sandholt CH, Jespersen NZ, Toft U, Madsen AL, Holstein-Rathlou von S, et al. 697 FGF21 Is a Sugar-Induced Hormone Associated with Sweet Intake and Preference in Humans. Cell 698 Metabolism. 2017;25:1045-6.

699

700

142. Han P, Keast RSJ, Roura E. Salivary leptin and TAS1R2/TAS1R3 polymorphisms are related to sweet taste sensitivity and carbohydrate intake from a buffet meal in healthy young adults. Br. J. Nutr. 2017;118:763-70. 